\title{
Impact of MIF Gene Promoter Variations on Risk of Rheumatic Heart Disease and Its Age of Onset in Saudi Arabian Patients
}

\author{
Atiyeh M. Abdallah ${ }^{1 *}$, Abdulhadi H. Al-Mazroea ${ }^{2}$, Waleed N. Al-Harbi ${ }^{2}$, \\ Nabeeh A. Al-Harbi' ${ }^{2}$ Amr E. Eldardear ${ }^{2}$, Yousef Almohammadi ${ }^{3}$ and Khalid M. Al-Harbi ${ }^{2}$ \\ ${ }^{1}$ West Midlands Regional Genetics Laboratory, Birmingham Women's NHS Foundation Trust, Birmingham, UK, ${ }^{2}$ Pediatric \\ Department, Maternity and Children Hospital, Ministry of Health, College of Medicine, Taibah University, Al-Madinah, Saudi \\ Arabia, ${ }^{3}$ Security Forces Medical Centre, Al-Madinah, Saudi Arabia
}

OPEN ACCESS

Edited by:

Susan Taylor Yeyeodu, North Carolina Central University, USA

Reviewed by: James Harris,

Monash University, Australia Sumanth D. Prabhu, University of Alabama at

Birmingham, USA

*Correspondence:

Atiyeh M. Abdallah

atiyeh.abdallah@bwnft.nhs.uk

Specialty section:

This article was submitted to Molecular Innate Immunity, a section of the journal

Frontiers in Immunology

Received: 17 December 2015 Accepted: 29 February 2016

Published: 14 March 2016

Citation:

Abdallah AM, Al-Mazroea $A H$, Al-Harbi WN, Al-Harbi NA, Eldardear AE, Almohammadi $Y$ and Al-Harbi KM (2016) Impact of MIF Gene Promoter Variations on Risk of Rheumatic Heart Disease and Its Age of Onset in Saudi Arabian Patients. Front. Immunol. 7:98. doi: 10.3389/fimmu.2016.00098
Although macrophage migration inhibitory factor (MIF) has consistently been shown to be an important immune modulator, data on the association between MIF promoter variations and the risk of developing rheumatic heart disease $(\mathrm{RHD})$ remain inconclusive. $\mathrm{RHD}$ is an important complication of streptococcal infections in the Middle East, not least in Saudi Arabia, and identifying risk markers is an important priority. Therefore, we investigated the association between two functional MIF promoter variations and RHD susceptibility and severity in Saudi patients: the MIF-173G > C substitution (rs755622) and the MIF-794 CATT 5-8 tetranucleotide repeat (rs5844572). Three hundred twenty-six individuals (124 RHD patients and 202 age-, sex-, and ethnically matched healthy controls) were genotyped using allelic discrimination and fragment analysis. Data were analyzed with respect to disease susceptibility, severity, sex, and age of onset. There was a significantly lower frequency of $173 \mathrm{C}$ allele carriage in $\mathrm{RHD}$ patients compared to controls [odds ratio $(\mathrm{OR})=0.47 ; 95 \%$ confidence intervals $(\mathrm{Cls})=0.28-0.77 ; p=0.003$ ] . Interestingly, the $173 \mathrm{C}$ allele was associated with late disease onset $(p=0.001)$. The 794 5-repeat allele was associated with decreased $\mathrm{RHD}$ risk (OR $=0.56$; 95\% Cls $=0.38$ $0.82 ; p=0.003)$. In contrast, the 7946 -repeat allele was associated with increased risk of $\mathrm{RHD}(\mathrm{OR}=1.7 ; 95 \% \mathrm{Cls}=1.2-2.5 ; p=0.002)$. MIF promoter variations appear to have a dual role in $\mathrm{RHD}$, with $173 \mathrm{C}$ allele non-carriers at higher risk of developing RHD at a younger age. These results require further validation in larger multi-ethnic cohorts, and functional studies are necessary to understand the underlying molecular mechanisms driving the at-risk phenotype.

Keywords: migration inhibitory factor, rheumatic heart disease, polymorphisms, age of onset, Saudi Arabia

\section{INTRODUCTION}

Rheumatic heart disease (RHD) is an autoimmune disease that can develop following throat infections with one of the group A beta-hemolytic streptococci (GAS). Although standard antibiotic treatments are effective and help to prevent the disease, RHD is a common source of acquired pediatric heart disease in many developing nations (1), to the extent that the World Health 
Organization (WHO) (2) and World Heart Federation (WHF) (3) recognize RHD as a neglected tropical disease (NTD). It is estimated that GAS infection is a major global human pathogen that causes morbidity and mortality only exceeded by HIV, TB, and malaria (4). RHD is also an important and ongoing cause of cardiac disease in indigenous populations in developed countries $(5,6)$. For example, in a hospital-based study of children admitted with rheumatic fever (RF), the precursor of RHD, in Saudi Arabia, carditis was reported in 53\% and severe carditis in $32 \%$ of cases (7). RF was more common in children from urban, low-income, and densely populated areas. In another study in western Saudi Arabia, Al-Sekait et al. assessed the prevalence of RHD in 9418 school children aged between 6 and 15 years (8) (representing $10 \%$ of the target population) and showed that RHD prevalence was 2.4/1000 (8). Molecular mimicry is thought to trigger RHD (9); however, the exact mechanisms underlying autoimmunity and cardiac tissue damage remain unknown.

Of note, only some GAS strains are rheumatogenic (10), and only $50 \%$ of individuals infected with these strains develop RHD (9). Furthermore, the disease appears to have a familial component: familial predisposition in RF was reported as early as 1889 by Cheadle, who estimated a five times greater risk of developing the disease in individuals with a family history compared to those without a family history (11). A meta-analysis of twin studies estimated that $60 \%$ of RF risk was heritable (12), which is higher than some other well-characterized complex autoimmune diseases (13). These data highlight the importance of a genetic component to the disease, and genetic variability in inflammatory and immune genes has been associated with RHD development and severity (10, 14-16).

Macrophage migration inhibitory factor (MIF) is a pleiotropic immune mediator important in innate and adaptive immune responses. MIF is a small gene $(<0.7 \mathrm{~kb})$ of three exons located on 22q11.2, and it is highly conserved across different species (17). MIF expression is rapidly induced by low concentrations of Gram-positive staphylococcal and streptococcal components (18), resulting in the production of a variety of cells types including macrophages, lymphocytes, and epithelial cells. MIF exerts a wide range of proinflammatory activities by upregulating expression of a variety of immune mediators including TLR4, IL-6, and TNF $\alpha(17,19)$ and overriding the immunosuppressive activity of glucocorticoids (17). Studies on infarcted myocardium have shown opposing actions for MIF depending on disease stage and its cellular source (20). For example, MIF is cardioprotective when cardiac ischemia/reperfusion is brief (21), but when ischemia is prolonged, MIF activates immune cells and increases inflammation (22).

The MIF promoter contains two functional variations that affect its gene expression and protein levels in vitro and in vivo: a MIF-173G > C substitution (rs755622) and a MIF-794 CATT S-8 tetranucleotide repeat (rs5844572) $(23,24)$. The C allele at the 173 position is associated with higher MIF expression in T cell lines; however, in a lung carcinoma cell line, the $G$ allele was associated with higher gene expression (25). In vitro and in vivo studies have shown that a greater number of CATT repeats are associated with higher gene expression $(17,24)$.
Migration inhibitory factor is pathogenic in several diseases including infectious (26), autoimmune (17), and cardiovascular diseases (20). In infectious diseases, MIF promotes pneumococcal clearance (26); however, MIF alleles that promote gene expression are associated with severe malarial anemia (27). MIF plays a dual role in autoimmune diseases; for example, alleles that promote gene expression protect against systemic lupus erythematosus (SLE) but, in patients with established disease, alleles that reduce expression protect against disease complications and multiple organ involvement (28). Studies on the genetic factors that contribute to RHD risk and severity are scarce, especially in the developed world. Therefore, we tested the hypothesis that MIF promoter variations modulate the course of RHD by evaluating these sequence variants in relation to RHD susceptibility, severity, and age of onset in 326 Saudi Arabian participants.

\section{MATERIALS AND METHODS}

\section{Study Population}

One hundred and twenty-four RHD patients were enrolled in a pilot study at the Pediatric Cardiology Clinic at the Maternity and Children Hospital, Al-Madinah region, Saudi Arabia between March 2013 and June 2014. The Maternity and Children Hospital ethics committee approved the study protocol, and the authors followed the norms of the World Medical Association Declaration of Helsinki. All adult patients and donors or the parents or guardians of child participants ( $<18$ years old) signed a fully informed and written consent form approved by the ethics committee.

The patient and control cohorts are described in previous studies $(15,16)$. Briefly, diagnosis was made according to the modified Jones criteria at initial diagnosis and confirmed by echocardiography (29). Patients were subgrouped according to echocardiographic findings into either mitral valve lesion (MVL) or multiple valve lesions including the mitral valve, termed a "combined valve lesion" (CVL). Exclusion criteria were patients with RF but without valvular disease, heart complications, or other inflammatory conditions. Age of onset was the age at which the patient had his/her first diagnosis confirmed by echocardiography. The control group was a random population sample of 202 healthy volunteers identified via the National Blood Service in the Al-Madinah region. Controls were age-, gender-, and ethnically matched unrelated volunteers with no history of cardiac or autoimmune diseases. All participants were of Saudi Arabian ethnicity.

\section{Genotyping MIF Promoter Polymorphisms}

DNA was purified from 2-ml whole blood using the QIAamp DNA Mini Kit (Qiagen, Hilden, Germany) according to the manufacturer's protocol. Extracted DNA was quantified by spectrophotometry (MaestroNano, MaestroGen, Las Vegas, NV, USA) and stored at $-20^{\circ} \mathrm{C}$ until use. The $M I F-173$ polymorphism was genotyped using the duplex quantitative TaqMan 5' Allelic Discrimination Assay (Applied Biosystems, Foster City, CA, USA; assay ID C_2213785_10) as directed by the manufacturer. Briefly, assays were performed in a final volume of $10 \mu \mathrm{l}$ (including TaqMan Genotyping Master Mix, 40× SNP Genotyping Assay Mix, DNase-free water, and 20-ng DNA) in 96-well plates using the following amplification protocol: $95^{\circ} \mathrm{C}$ 
for $10 \mathrm{~min}$ followed by 50 cycles at $95^{\circ} \mathrm{C}$ for $15 \mathrm{~s}$ and $60^{\circ} \mathrm{C}$ for $1 \mathrm{~min}$ (annealing/extension). Fluorescence detection took place at $60^{\circ} \mathrm{C}$. Non-template controls were included in each run. The genotype call rate was over $99 \%$. Duplicate genotyping of $10 \%$ of samples selected at random was performed for quality control. Assays were performed using the StepOnePlus system, and the automated Sequence Detection Software (SDS) v2.3 was used for auto-calling (Applied Biosystems).

The MIF-794 repeat was genotyped by conventional PCR, and the product was separated by capillary electrophoresis (3500 Genetic Analyzer, Life Technologies, Carlsbad, CA, USA). Reactions were performed with 10 pmol of each primer: forward primer (FAM-5'-AAATCTCTGAGGACCTGGCC-3') and reverse primer ( $5^{\prime}$-CACCGTGTATGGCCTCTCAT- $\left.3^{\prime}\right)$ designed using Primer $3 .{ }^{1}$ PCR products were detected by capillary electrophoresis using the fluorescently labeled forward primer. Amplifications were carried out in a $10-\mu \mathrm{l}$ reaction volume containing 30 -ng genomic DNA in $2 \times$ Go-Taq Master Mix including $\mathrm{MgCl}_{2}, 10 \times$ PCR buffer, dNTPs, and 10 units of Taq DNA polymerase (M7132, Promega, Madison, WI, USA). Samples were amplified using the Veriti thermal cycler (Life Technologies, Carlsbad, CA, USA). The cycling and amplification conditions were initial denaturation at $95^{\circ} \mathrm{C}$ for 2 min followed by 35 cycles with denaturation at $95^{\circ} \mathrm{C}$ for $15 \mathrm{~s}$, annealing at $60^{\circ} \mathrm{C}$ for $15 \mathrm{~s}$, and extension at $72^{\circ} \mathrm{C}$ for $30 \mathrm{~s}$. Automated capillary electrophoresis on the 3500 Genetic Analyzer was performed for each sample following the manufacturer's protocol, and the CATT alleles were identified using GeneMapper v4.1 software (Life Technologies).

\section{Statistical Analysis}

Statistical analyses were conducted using SPSS version 17 (IBM Statistics, Chicago, IL, USA). In addition, results were confirmed using a freely available online statistical tool, VassarStats. ${ }^{2}$ Genotyping data were checked for any deviation from HardyWeinberg equilibrium (HWE) using chi-squared contingency tables. Genotype and allele frequencies were determined by direct counting in patients and controls. Significant differences in the distribution of MIF promoter polymorphisms between cases and controls were tested using chi-squared contingency tables or Fisher's exact test as appropriate. Linear regression was used to test for any association between the genetic variations and age of onset (the dependent variable was age of onset and allele frequencies were predictors). Odds ratios (ORs) and 95\% confidence intervals (CIs) were calculated. A $p$-value $<0.05$ was considered statistically significant.

\section{RESULTS}

\section{Patient Characteristics}

The demographic and baseline characteristics of the patients at disease presentation according to echocardiographic findings are presented in Table 1. Three hundred twenty-six Saudi Arabian individuals (202 controls and 124 patients) were genotyped for the

\footnotetext{
${ }^{1}$ http://primer3.ut.ee/
}

${ }^{2}$ www.vassarstats.net
MIF-173 (rs755622) and MIF-794 (rs5844572) polymorphisms. RHD patients were $56 \%$ males and $44 \%$ females, and 67 patients (54\%) had MVL and 57 patients (46\%) had CVL. Carditis (64\%) and arthritis (57\%) were present in the majority of patients. Acute phase reactants were elevated in $79 \%$ of patients at presentation (Table 1).

\section{Distribution of MIF Polymorphisms}

The genotypes, allele frequencies, and allele carriage distributions are shown in Table 2. There were no deviations from the HWE in patients or controls for either MIF variant. The genotype and haplotype frequencies of MIF promoter polymorphisms in the control group were consistent with similar published studies from other countries; however, this is the first report of frequencies of these polymorphisms in a Saudi Arabian or Arab population. The allelic frequencies of the 173 polymorphism in healthy controls were similar to those reported in studies from Turkey, the Netherlands, and Caucasians from New Zealand (30-32), but different to those reported in a Mexican population (33). Similarly, distributions of the 5-, 6-, 7-, and 8-CATT alleles located at the 794 locus were comparable to those reported from Italy and Belgium (34), but different to Mexican and Japanese populations $(33,35)$.

\section{Relationship between MIF Polymorphisms and RHD}

The MIF polymorphism genotype and allele frequencies were different in patients with RHD. There was a significant difference in the distribution of the $M I F-173$ genotype frequency between

TABLE 1 | Demographic characteristics and clinical details of the patients $(n=124)$ and controls $(n=202)$.

\begin{tabular}{lc}
\hline Parameter & Value \\
\hline Average age (mean \pm SD years) & \\
Controls & $20.5 \pm 4.2$ \\
Patients (at follow-up) & $19 \pm 5$ \\
Patients (age of onset at diagnosis) & $7.9 \pm 2.4$ \\
Gender: male/female (\%) & \\
Controls & $55 / 45$ \\
Patients & $56 / 44$
\end{tabular}

Clinical manifestations

$N$ cases $(\%)$

Characteristics
Valvular lesion
Mitral valve lesion (MVL)
Combined valve lesion (CVL)
Carditis
Arthritis
Chorea
Skin rash
Subcutaneous nodules
Recurrence

Recurrence

$N$, number; $N$ cases, number of cases; NA, not available; CRP, C-reactive protein; ESR, erythromycin sedimentation rate. 
patients and controls $\left(\chi^{2}=10.2, p=0.006\right.$; Table 2). MIF-173C allele frequencies were associated with a decrease in RHD risk $\left(\chi^{2}=11.5, p=0.0007, \mathrm{OR}=0.48,95 \%\right.$ CIs 0.31-0.74). Likewise, $173 \mathrm{C}$ allele carriage (CC + GC vs. GG) was associated with a decreased risk of developing $\operatorname{RHD}\left(\chi^{2}=9.1, p=0.003, \mathrm{OR}=0.47\right.$, 95\% CIs 0.28-0.77).

The genotypic and allelic frequencies for the MIF-794 CATT ${ }_{5-8}$ repeat variation in RHD and healthy subjects are shown in Table 3. On the one hand, the $794 \mathrm{CATT}_{5}$-allelic frequencies were significantly higher in the control group than RHD patients $\left(\chi^{2}=8.8, p=0.003, \mathrm{OR}=0.56,95 \%\right.$ CIs $\left.0.38-0.82\right)$. On the other hand, $794 \mathrm{CATT}_{6}$-allelic frequencies were associated with an increased risk of developing $\mathrm{RHD}\left(\chi^{2}=9.7, p=0.002, \mathrm{OR}=1.7\right.$,
95\% CIs 1.2-2.5). Most evidence indicates that $794 \mathrm{CATT}_{6-8}$ repeats have higher transcriptional activity than $794 \mathrm{CATT}_{5}$ repeats; therefore, we grouped $794 \mathrm{CATT}_{6-8}$ repeats and termed them the $\mathrm{X}$ allele. X-allele frequency was more common in RHD subjects than in healthy controls $\left(\chi^{2}=8.8, p=0.003, \mathrm{OR}=1.8\right.$, 95\% CIs 1.22-2.66).

\section{MIF Genotype Distribution and Age of Disease Onset}

In linear regression analysis, the age of onset was significantly greater for $M I F-173 \mathrm{C}$ allele carriers than non-MIF-173C allele carriers in RHD patients $(p=0.001$; Figure 1). The mean ages

\begin{tabular}{|c|c|c|c|c|c|c|c|c|}
\hline \multirow[t]{2}{*}{$M I F-173$} & \multicolumn{2}{|c|}{ Control $(N=202)$} & \multicolumn{2}{|c|}{ Patients $(N=124)$} & \multirow[t]{2}{*}{$\chi^{2}$} & \multirow[t]{2}{*}{ df } & \multirow[t]{2}{*}{$p$-value } & \multirow[t]{2}{*}{ OR $(95 \% \mathrm{Cl})$} \\
\hline & Count & Frequency & Count & Frequency & & & & \\
\hline \multicolumn{9}{|l|}{ Genotype } \\
\hline GG & 122 & 0.60 & 95 & 0.77 & 10.2 & 2 & 0.006 & \\
\hline GC & 64 & 0.32 & 26 & 0.21 & & & & \\
\hline $\mathrm{CC}$ & 16 & 0.08 & 3 & 0.02 & & & & \\
\hline \multicolumn{9}{|l|}{ Allele frequency } \\
\hline G & 308 & 0.76 & 216 & 0.87 & Ref. & & & \\
\hline C & 96 & 0.24 & 32 & 0.13 & 11.5 & 1 & 0.0007 & $0.48(0.31-0.74)$ \\
\hline \multicolumn{9}{|l|}{ Allele carriage } \\
\hline$(G G+G C)$ vs. $C C$ & 186 & 0.92 & 121 & 0.98 & 4.2 & 1 & 0.04 & $3.5(0.99-12.2)$ \\
\hline$(C C+G C)$ vs. $G G$ & 80 & 0.4 & 29 & 0.23 & 9.1 & 1 & 0.003 & $0.47(0.28-0.77)$ \\
\hline
\end{tabular}

Significant findings are shown in bold; N, number.

TABLE 3 | Distribution of MIF-794 repeat genotypes and allele frequencies in patients and controls.

\begin{tabular}{|c|c|c|c|c|c|c|c|}
\hline \multirow[t]{2}{*}{ MIF-794[CATT] } & \multicolumn{2}{|c|}{ Control $(N=202)$} & \multicolumn{2}{|c|}{ Patients $(N=124)$} & \multirow[t]{2}{*}{$\chi^{2}$} & \multirow[t]{2}{*}{$p$-value } & \multirow[t]{2}{*}{ OR (95\% Cls) } \\
\hline & Count & Frequency & Count & Frequency & & & \\
\hline \multicolumn{8}{|l|}{ Genotype } \\
\hline $5 / 5$ & 19 & 0.09 & 3 & 0.02 & 5.96 & 0.02 & $0.24(0.07-0.82)$ \\
\hline $5 / 6$ & 64 & 0.32 & 35 & 0.28 & 0.4 & 0.5 & $0.9(0.5-1.4)$ \\
\hline $5 / 7$ & 7 & 0.03 & 3 & 0.02 & 0.3 & 0.6 & $0.7(0.18-2.7)$ \\
\hline $5 / 8$ & 4 & 0.02 & 0 & 0.00 & 2.5 & 0.1 & $0.98(0.96-1)$ \\
\hline $6 / 6$ & 82 & 0.41 & 69 & 0.56 & 7.0 & 0.008 & $1.8(1.17-2.9)$ \\
\hline $6 / 7$ & 18 & 0.09 & 10 & 0.08 & 0.07 & 0.8 & $0.9(0.4-2)$ \\
\hline $6 / 8$ & 6 & 0.03 & 1 & 0.01 & - & 0.3 & - \\
\hline $7 / 7$ & 2 & 0.01 & 2 & 0.02 & - & 0.6 & - \\
\hline $7 / 8$ & 0 & 0.00 & 0 & 0.00 & - & - & - \\
\hline $8 / 8$ & 0 & 0.00 & 1 & 0.01 & - & - & - \\
\hline \multicolumn{8}{|l|}{$X$ allele carriage } \\
\hline$(5 / 5+5 / X)$ vs. $X / X$ & 94 & 0.47 & 41 & 0.33 & 5.7 & 0.02 & $0.57(0.36-0.9)$ \\
\hline$(X / X+5 / X)$ vs. $5 / 5$ & 183 & 0.91 & 121 & 0.98 & 6.0 & 0.01 & $4.2(1.2-14.5)$ \\
\hline \multicolumn{8}{|l|}{ Allele freq. } \\
\hline 5 & 113 & 0.28 & 44 & 0.18 & 8.8 & 0.003 & $0.56(0.38-0.82)$ \\
\hline 6 & 252 & 0.62 & 184 & 0.74 & 9.7 & 0.002 & $1.7(1.2-2.5)$ \\
\hline 7 & 29 & 0.07 & 17 & 0.07 & 0.03 & 0.9 & $1(0.51-1.8)$ \\
\hline 8 & 10 & 0.02 & 3 & 0.01 & - & 0.4 & - \\
\hline$X$ allele freq. & 291 & 0.82 & 204 & 0.72 & 8.8 & 0.003 & $1.8(1.22-2.66)$ \\
\hline
\end{tabular}

Significant findings are shown in bold; N, number; $X$ refers to 794 CATT alleles 6-8. 


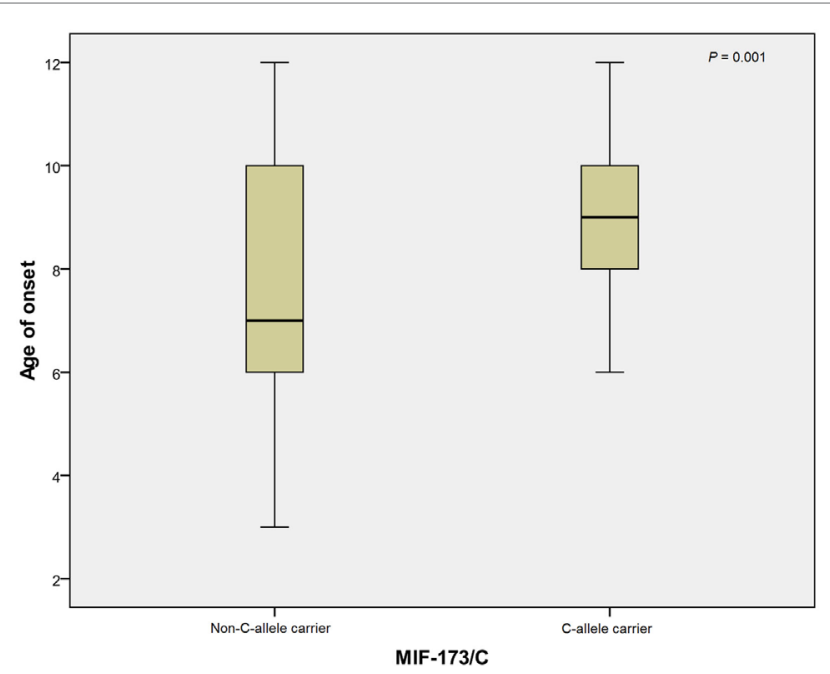

FIGURE 1 Mean of age at onset for $173 \mathrm{C}$ allele non-carriers $(N=94)$ and carriers $(\mathbf{N}=\mathbf{2 8})$. The mean age at onset of non-C allele carriers and $C$ allele carriers were $7.5 \pm 2.4$ and $9.2 \pm 1.6$, respectively. $N$, number.

of onset of C-allele carriers and non-carriers were $9.2 \pm 1.6$ and $7.5 \pm 2.4$, respectively. There was no significant association between the tetranucleotide variation and disease age of onset (data not shown).

\section{DISCUSSION}

Accumulation of deleterious and disease-associated genetic variations in immune genes has been linked to autoimmune disease susceptibility (36). RHD is a multifactorial disorder involving multiple genetic and environmental factors. Although it remains a common autoimmune heart disease in children in developing countries, only a few studies from these regions have explored the influence of genetic variations in immune genes in RHD (37).

In this pilot case-control study, the impact of MIF functional variations was evaluated with respect to RHD susceptibility and severity in 326 Saudi Arabian individuals (202 controls and 124 patients). We report that the pleiotropic inflammatory cytokine MIF exerts dual effects in RHD patients. The $173 \mathrm{C}$ allele was associated with reduced RHD risk and, interestingly, this genotype was associated with later disease onset. In contrast, the 794 $\mathrm{CATT}_{6}$ allele was associated with increased RHD risk, but the $794 \mathrm{CATT}_{5}$ allele was associated with reduced RHD risk. Genetic variability in MIF may have a dual impact on the development of RHD in the Saudi Arabian population.

The pleiotropic roles of MIF and MIF alleles on the immunopathogenesis of infectious and autoimmune diseases have been documented. For example, in SLE, MIF alleles associated with higher gene expression (173C and 794 extended alleles) are associated with a lower risk of SLE (38). However, in patients with established disease, lower expression alleles are associated with reduced end-stage organ involvement (28). Interestingly, the MIF-173C allele has been associated with a lower incidence of antinuclear antibody (ANA) development in SLE, supporting a protective role for MIF in SLE (17). On the other hand, a metaanalysis has shown that 173 polymorphisms are a risk factor for inflammatory bowel disease; however, due to a lack of clinical details and original data, the effect of MIF polymorphisms on disease progression and severity could not be analyzed (39). Similarly, MIF-794 allele 7 has been shown to be a risk factor for the development of rheumatoid arthritis; however, 794 allele 5 is correlated to reduced disease severity $(33,40)$. In another autoimmune disease, systemic sclerosis, the MIF-173 polymorphism was associated with the development of the diffuse and more severe form of the disease in a large meta-analysis (41). The role of MIF in different diseases is clearly highly cell- and disease-context dependent.

MIF polymorphisms and protein expression also have an impact on outcomes in patients with infectious diseases. In African and Indian studies, longer CATT repeats were associated with malarial complications, such as severe malarial anemia (27) and cerebral malaria (42), which are the main causes of death in these patients. Interestingly, the frequency of the shortest CATT-5 repeat was greatest in African populations, leading to the speculation that MIF low expression alleles may be protective against malaria, similar to the effect seen with sickle hemoglobin (HbS) genes (17).

To our knowledge, this is the first case-control study of the impact of MIF promoter variations on RHD risk. One Turkish study explored the influence of the 173 polymorphism on acute $\mathrm{RF}$, the precursor of RHD, and reported that the polymorphism conferred increased risk (43). However, the authors did not report any clinical details on RHD in this cohort. Unfortunately, we could not examine the effect of MIF on RF since our patients were recruited from a tertiary cardiac center that only receives patients with established valvular disease. Nevertheless, it has been shown that MIF plays an important role in heart disease (44). In myocardial infarction (MI), myocardiocyte-secreted MIF exerts a protective effect when cardiac ischemia is brief by activating AMP-activated protein kinase (AMPK) and stress suppression (44). AMPK phosphorylation promotes glucose uptake via glucose transporter-4 (GLUT4), thereby providing metabolic protection (45). However, in prolonged ischemia, MIF activates immune cells and increases inflammation, cardiac remodeling, and fibrosis by promoting matrix protein synthesis by myofibroblasts (45). In RHD, valvular damage is caused by recurrent rheumatic insults. In some patients, persistent inflammation leads to the formation of Aschoff bodies, which are granulomatous lesions characterized by mononuclear cell and macrophage infiltrates in the myocardium and endocardium. Over the disease course, the valves become thickened and, eventually, stenosed. MIF's role in these inflammatory foci has yet to be studied, but it is possible that, in the early stages of the disease, MIF might help to clear certain pathogens and apoptotic cells (46). In turn, this could help to protect cardiomyocytes and delay valvular damage. Conversely, recurrent rheumatic insults in the presence of MIF may increase inflammatory cell recruitment and promote proinflammatory mediators, thereby enhancing regional inflammation and damaging cardiac tissue.

Of particular note, the MIF-173C allele was associated with later disease onset as well as decreased risk of RHD. To our knowledge, 
this is the first study to examine the effect of polymorphisms on the age of onset of RHD. These data suggest that MIF action may be age dependent; however, the results must be considered with caution since there are different definitions of "age of onset," and advanced diagnostic echocardiography has influenced RHD burden data $(47,48)$. Several studies have shown that MIF is age dependent in other diseases: adults with a low-expressing MIF allele (CATT5) are at high risk of Gram-negative bacterial infections (49) and high-expressing MIF genotypes protect older patients from sepsis mortality (50). In animal models, the protective role of MIF during ischemic injury is abolished in senescent hearts, an effect correlated to impaired AMPK activation and low MIF expression levels (51). Interestingly, exogenous MIF can effectively rejuvenate stem cells isolated from age-induced senescent animals (52). Clearly, MIF variations influence disease severity and progression; therefore, future clinical studies need to collect and analyze data that includes disease stage and patient age.

Here, we report an association between MIF promoter variations and RHD. These findings require replication in larger, multi-ethnic studies to overcome some of the ethnic bias in our study, the retrospective analysis, and to provide sufficient power for robust subgroup analysis. Furthermore, we only analyzed two polymorphisms and not the entire MIF gene, and it would be useful to analyze other MIF polymorphisms and functional genetic variations in downstream signaling pathways to fully

\section{REFERENCES}

1. Steer AC, Carapetis JR. Prevention and treatment of rheumatic heart disease in the developing world. Nat Rev Cardiol (2009) 6:689-98. doi:10.1038/ nrcardio.2009.162

2. Wyber R, Zühlke L, Carapetis J. The case for global investment in rheumatic heart-disease control. Bull World Health Organ (2014) 92:768-70. doi:10.2471/ BLT.13.134486

3. Remenyi B, Carapetis J, Wyber R, Taubert K, Mayosi BM, Federation WH. Position statement of the World Heart Federation on the prevention and control of rheumatic heart disease. Nat Rev Cardiol (2013) 10:284-92. doi:10.1038/nrcardio.2013.34

4. Carapetis JR, Steer AC, Mulholland EK, Weber M. The global burden of group A streptococcal diseases. Lancet Infect Dis (2005) 5:685-94. doi:10.1016/ S1473-3099(05)70267-X

5. Roberts K, Colquhoun S, Steer A, Reményi B, Carapetis J. Screening for rheumatic heart disease: current approaches and controversies. Nat Rev Cardiol (2013) 10:49-58. doi:10.1038/nrcardio.2012.157

6. Russell EA, Tran L, Baker RA, Bennetts JS, Brown A, Reid CM, et al. A review of outcome following valve surgery for rheumatic heart disease in Australia. BMC Cardiovasc Disord (2015) 15:103. doi:10.1186/s12872-015-0094-1

7. Qurashi MA. The pattern of acute rheumatic fever in children: experience at the children's hospital, Riyadh, Saudi Arabia. J Saudi Heart Assoc (2009) 21:215-20. doi:10.1016/j.jsha.2009.10.004

8. al-Sekait MA, Al-Sweliem AA, Tahir M. Rheumatic heart disease in schoolchildren in western district, Saudi Arabia. J R Soc Health (1990) 110(15-16):19. doi:10.1177/146642409011000109

9. Guilherme L, Kalil J. Rheumatic heart disease: molecules involved in valve tissue inflammation leading to the autoimmune process and anti-S. pyogenes vaccine. Front Immunol (2013) 4:352. doi:10.3389/fimmu.2013.00352

10. Bryant PA, Robins-Browne R, Carapetis JR, Curtis N. Some of the people, some of the time: susceptibility to acute rheumatic fever. Circulation (2009) 119:742-53. doi:10.1161/CIRCULATIONAHA.108.792135

11. Cheadle WB. The Various Manifestations of the Rheumatic State as Exemplified in Childhood and Early Life. Lectures, etc. London: Smith, Elder \& Co. (1889). elucidate the function of this pathway in RHD. Finally, studies from Arab countries are scarce with respect to $M I F$ variations in any infectious or autoimmune diseases, making ethnic comparisons difficult and only permitting comparisons with results from non-Arab populations.

In conclusion, $M I F$ promoter variants may have an impact on RHD susceptibility, severity, and age of onset. Further prospective, multi-ethnic studies are required.

\section{AUTHOR CONTRIBUTIONS}

AA designed the study, planned and performed experiments, analyzed data, and wrote the manuscript. NA-H and AA-M collected patient samples and clinical data and contributed to research discussion. AE and WA-H analyzed data and edited the manuscript. YA and KA-H designed the study, contributed to research discussion, and edited the manuscript.

\section{ACKNOWLEDGMENTS}

The authors are grateful to all patients and controls for their cooperation. The authors also thank all nurses at Pediatric Cardiology Unit, Maternity and Children Hospital, for their help in sample collection. We gratefully acknowledge editorial assistance from Nextgenediting (www.nextgenediting.com).

12. Engel ME, Stander R, Vogel J, Adeyemo AA, Mayosi BM. Genetic susceptibility to acute rheumatic fever: a systematic review and meta-analysis of twin studies. PLoS One (2011) 6:e25326. doi:10.1371/journal.pone.0025326

13. Selmi C, Lu Q, Humble MC. Heritability versus the role of the environment in autoimmunity. J Autoimmun (2012) 39:249-52. doi:10.1016/j.jaut.2012.07.011

14. Zheng RL, Zhang H, Jiang WL. Tumor necrosis factor-alpha $308 \mathrm{G}>\mathrm{A}$ polymorphism and risk of rheumatic heart disease: a meta-analysis. Sci Rep (2014) 4:4731. doi:10.1038/srep04731

15. Abdallah AM, Alnuzha A, Al-Mazroea AH, Eldardear AE, Alsamman AY, Almohammadi Y, et al. IL10 promoter polymorphisms are associated with rheumatic heart disease in Saudi Arabian patients. Pediatr Cardiol (2015) 37(1):99-105. doi:10.1007/s00246-015-1245-y

16. Al-Harbi KM, Almuzaini IS, Morsy MM, Abdelaziz NA, Al-Balawi AM, Abdallah AM. Angiotensin-converting enzyme gene insertion/deletion polymorphism in Saudi patients with rheumatic heart disease. Saudi Med J (2015) 36:176-80. doi:10.15537/smj.2015.2.10267

17. Bucala R. MIF, MIF alleles, and prospects for therapeutic intervention in autoimmunity. JClin Immunol (2013) 33(Suppl 1):S72-8. doi:10.1007/ s10875-012-9781-1

18. Calandra T, Spiegel LA, Metz CN, Bucala R. Macrophage migration inhibitory factor is a critical mediator of the activation of immune cells by exotoxins of Gram-positive bacteria. Proc Natl Acad Sci U S A (1998) 95:11383-8. doi:10.1073/pnas.95.19.11383

19. Roger T, David J, Glauser MP, Calandra T. MIF regulates innate immune responses through modulation of toll-like receptor 4. Nature (2001) 414:920-4. doi:10.1038/414920a

20. White DA, Su Y, Kanellakis P, Kiriazis H, Morand EF, Bucala R, et al. Differential roles of cardiac and leukocyte derived macrophage migration inhibitory factor in inflammatory responses and cardiac remodelling post myocardial infarction. J Mol Cell Cardiol (2014) 69:32-42. doi:10.1016/j.yjmcc.2014.01.015

21. Qi D, Hu X, Wu X, Merk M, Leng L, Bucala R, et al. Cardiac macrophage migration inhibitory factor inhibits JNK pathway activation and injury during ischemia/reperfusion. J Clin Invest (2009) 119:3807-16. doi:10.1172/JCI39738

22. Gao XM, Liu Y, White D, Su Y, Drew BG, Bruce CR, et al. Deletion of macrophage migration inhibitory factor protects the heart from severe 
ischemia-reperfusion injury: a predominant role of anti-inflammation. J Mol Cell Cardiol (2011) 50:991-9. doi:10.1016/j.yjmcc.2010.12.022

23. Radstake TR, Sweep FC, Welsing P, Franke B, Vermeulen SH, GeurtsMoespot A, et al. Correlation of rheumatoid arthritis severity with the genetic functional variants and circulating levels of macrophage migration inhibitory factor. Arthritis Rheum (2005) 52:3020-9. doi:10.1002/ art. 21285

24. Adamali H, Armstrong ME, Mclaughlin AM, Cooke G, Mckone E, Costello $\mathrm{CM}$, et al. Macrophage migration inhibitory factor enzymatic activity, lung inflammation, and cystic fibrosis. Am J Respir Crit Care Med (2012) 186:162-9. doi:10.1164/rccm.201110-1864OC

25. Donn R, Alourfi Z, De Benedetti F, Meazza C, Zeggini E, Lunt M, et al. Mutation screening of the macrophage migration inhibitory factor gene: positive association of a functional polymorphism of macrophage migration inhibitory factor with juvenile idiopathic arthritis. Arthritis Rheum (2002) 46:2402-9. doi:10.1002/art.10492

26. Weiser JN, Roche AM, Hergott CB, Larose MI, Connolly T, Jorgensen WL, et al. Macrophage migration inhibitory factor is detrimental in pneumococcal pneumonia and a target for therapeutic immunomodulation. J Infect Dis (2015) 212:1677-82. doi:10.1093/infdis/jiv262

27. Awandare GA, Martinson JJ, Were T, Ouma C, Davenport GC, Ong'echa JM, et al. MIF (macrophage migration inhibitory factor) promoter polymorphisms and susceptibility to severe malarial anemia. J Infect Dis (2009) 200:629-37. doi:10.1086/600894

28. Sreih A, Ezzeddine R, Leng L, Lachance A, Yu G, Mizue Y, et al. Dual effect of the macrophage migration inhibitory factor gene on the development and severity of human systemic lupus erythematosus. Arthritis Rheum (2011) 63:3942-51. doi:10.1002/art.30624

29. Ferrieri P, Group JCW. Proceedings of the Jones criteria workshop. Circulation (2002) 106:2521-3. doi:10.1161/01.CIR.0000037745.65929.FA

30. Col-Araz N, Oguzkan-Balci S, Baspinar O, Sever T, Balat A, Pehlivan S. Mannose binding lectin and macrophage migration inhibitory factor gene polymorphisms in Turkish children with cardiomyopathy: no association with MBL2 codon 54 A/B genotype, but an association between MIF-173 CC genotype. Int J Med Sci (2012) 9:506-12. doi:10.7150/ijms.4787

31. Falvey JD, Bentley RW, Merriman TR, Hampton MB, Barclay ML, Gearry RB, et al. Macrophage migration inhibitory factor gene polymorphisms in inflammatory bowel disease: an association study in New Zealand Caucasians and meta-analysis. World J Gastroenterol (2013) 19:6656-64. doi:10.3748/wjg. v19.i39.6656

32. Karakaya B, Van Moorsel CH, Van Der Helm-Van Mil AH, Huizinga TW, Ruven HJ, Van Der Vis JJ, et al. Macrophage migration inhibitory factor (MIF)-173 polymorphism is associated with clinical erythema nodosum in Löfgren's syndrome. Cytokine (2014) 69:272-6. doi:10.1016/j. cyto.2014.05.020

33. Llamas-Covarrubias MA, Valle $\mathrm{Y}$, Bucala R, Navarro-Hernández RE, Palafox-Sánchez CA, Padilla-Gutiérrez JR, et al. Macrophage migration inhibitory factor (MIF): genetic evidence for participation in early onset and early stage rheumatoid arthritis. Cytokine (2013) 61:759-65. doi:10.1016/j. cyto.2012.12.032

34. Melotti P, Mafficini A, Lebecque P, Ortombina M, Leal T, Pintani E, et al. Impact of MIF gene promoter polymorphism on F508del cystic fibrosis patients. PLoS One (2014) 9:e114274. doi:10.1371/journal.pone.0114274

35. Nishihira J, Sakaue S. Overview of macrophage migration inhibitory factor (MIF) as a potential biomarker relevant to adiposity. J Tradit Complement Med (2012) 2:186-91.

36. Seldin MF. The genetics of human autoimmune disease: a perspective on progress in the field and future directions. JAutoimmun (2015) 64:1-12. doi:10.1016/j.jaut.2015.08.015

37. Maurice J. Rheumatic heart disease back in the limelight. Lancet (2013) 382:1085-6. doi:10.1016/S0140-6736(13)61972-8

38. Lang T, Foote A, Lee JP, Morand EF, Harris J. MIF: implications in the pathoetiology of systemic lupus erythematosus. Front Immunol (2015) 6:577. doi:10.3389/fimmu.2015.00577
39. Yang J, Li Y, Zhang X. Meta-analysis of macrophage migration inhibitory factor (MIF) gene-173G/C polymorphism and inflammatory bowel disease (IBD) risk. Int J Clin Exp Med (2015) 8:9570-4.

40. Baugh JA, Chitnis S, Donnelly SC, Monteiro J, Lin X, Plant BJ, et al. A functional promoter polymorphism in the macrophage migration inhibitory factor (MIF) gene associated with disease severity in rheumatoid arthritis. Genes Immun (2002) 3:170-6. doi:10.1038/sj.gene.6363867

41. Bossini-Castillo L, Simeon CP, Beretta L, Vonk MC, Callejas-Rubio JL, Espinosa G, et al. Confirmation of association of the macrophage migration inhibitory factor gene with systemic sclerosis in a large European population. Rheumatology (2011) 50:1976-81. doi:10.1093/rheumatology/ker259

42. Tha AN, Sundaravadivel P, Pati SS, Patra PK, Thangaraj K. Variations in ncRNA gene LOC284889 and MIF-794CATT repeats are associated with malaria susceptibility in Indian populations. Malar $J$ (2013) 12:345. doi:10.1186/1475-2875-12-345

43. Col-Araz N, Pehlivan S, Baspinar O, Sever T, Oguzkan-Balci S, Balat A. Association of macrophage migration inhibitory factor and mannose-binding lectin-2 gene polymorphisms in acute rheumatic fever. Cardiol Young (2013) 23:486-90. doi:10.1017/S1047951112000972

44. Miller EJ, Li J, Leng L, Mcdonald C, Atsumi T, Bucala R, et al. Macrophage migration inhibitory factor stimulates AMP-activated protein kinase in the ischaemic heart. Nature (2008) 451:578-82. doi:10.1038/nature06504

45. Dayawansa NH, Gao XM, White DA, Dart AM, Du XJ. Role of MIF in myocardial ischaemia and infarction: insight from recent clinical and experimental findings. Clin Sci (2014) 127:149-61. doi:10.1042/CS20130828

46. Das R, Larose MI, Hergott CB, Leng L, Bucala R, Weiser JN. Macrophage migration inhibitory factor promotes clearance of pneumococcal colonization. J Immunol (2014) 193:764-72. doi:10.4049/jimmunol.1400133

47. Reményi B, Wilson N, Steer A, Ferreira B, Kado J, Kumar K, et al. World Heart Federation criteria for echocardiographic diagnosis of rheumatic heart disease - an evidence-based guideline. Nat Rev Cardiol (2012) 9:297-309. doi:10.1038/nrcardio.2012.7

48. Gewitz MH, Baltimore RS, Tani LY, Sable CA, Shulman ST, Carapetis J, et al. Revision of the Jones criteria for the diagnosis of acute rheumatic fever in the era of Doppler echocardiography: a scientific statement from the American Heart Association. Circulation (2015) 131:1806-18. doi:10.1161/ CIR.0000000000000205

49. Das R, Subrahmanyan L, Yang IV, Van Duin D, Levy R, Piecychna M, et al. Functional polymorphisms in the gene encoding macrophage migration inhibitory factor are associated with Gram-negative bacteremia in older adults. J Infect Dis (2014) 209:764-8. doi:10.1093/infdis/jit571

50. Lehmann LE, Book M, Hartmann W, Weber SU, Schewe JC, Klaschik S, et al. A MIF haplotype is associated with the outcome of patients with severe sepsis: a case control study. J Transl Med (2009) 7:100. doi:10.1186/1479-5876-7-100

51. Ma H, Wang J, Thomas DP, Tong C, Leng L, Wang W, et al. Impaired macrophage migration inhibitory factor-AMP-activated protein kinase activation and ischemic recovery in the senescent heart. Circulation (2010) 122:282-92. doi:10.1161/CIRCULATIONAHA.110.953208

52. Xia W, Zhang F, Xie C, Jiang M, Hou M. Macrophage migration inhibitory factor confers resistance to senescence through CD74-dependent AMPKFOXO3a signaling in mesenchymal stem cells. Stem Cell Res Ther (2015) 6:82. doi:10.1186/s13287-015-0076-3

Conflict of Interest Statement: The authors declare that the research was conducted in the absence of any commercial or financial relationships that could be construed as a potential conflict of interest.

Copyright (ㅇ 2016 Abdallah, Al-Mazroea, Al-Harbi, Al-Harbi, Eldardear, Almohammadi and Al-Harbi. This is an open-access article distributed under the terms of the Creative Commons Attribution License (CC BY). The use, distribution or reproduction in other forums is permitted, provided the original author (s) or licensor are credited and that the original publication in this journal is cited, in accordance with accepted academic practice. No use, distribution or reproduction is permitted which does not comply with these terms. 